\title{
Chemical Characteristics and Immuno-stimulating Properties of Biopolymers Extracted from Acanthopanax sessiliflorus
}

\author{
Sang-Chul Jeong, Young-Tae Jeong, Byung-Keun Yang and Chi-Hyun Song* \\ Department of Biotechnology, Daegu University, Gyungsan, Gyungbuk 712-714, Korea
}

Received 28 October 2005, Accepted 14 November 2005

\begin{abstract}
During our search for macrophage stimulating compounds from medicinal plants, we isolated biopolymers from Acanthopanax sessiliflorus. Isolated fraction AS-5 showed maximum potential, and stimulated lysosonal enzymatic activity by $230 \%$ at $300 \mu \mathrm{g} / \mathrm{ml}$. The nitric oxide (NO) producing ability of AS-5 $100 \mu \mathrm{g} / \mathrm{ml}$ was $58 \mu \mathrm{M}$ when treated with interferon- $\gamma$ and lipopolysaccharide $20 \mu \mathrm{g} / \mathrm{ml}$. The lymphocyte proliferating effects of isolated biopolymer fractions were also investigated. Highest lymphoproliferative activity (a 2.8-fold enhancement compared to saline treated group was exhibited by AS-3 at $200 \mu \mathrm{g} / \mathrm{ml}$ followed by AS-5 and AS-6. The AS-3 fraction stimulated only T-lymphocytes and had little or no effect on B-lymphocyte proliferation. Partially methylated alditol acetates were prepared to elucidate the glycosyl linkage-compositions of the AS-3 and AS-5 biopolymers, and were analyzed by GC-MS. The AS-3 and AS-5 biopolymer fractions were found to contain 2,3,4tri- $O$-methyl-D-glucitol, 2,3,4-tri- $O$-methyl-D-galacitol 3,4,6tri- $O$-methyl-galacitol, 2- $O$-methyl-arabinitol and 2,4,6-tri$O$-methyl-D-glucitol, 2,3,6-tri- $O$-methyl-D-galacitol linkages, respectively.
\end{abstract}

Keywords: Acanthopanax sessiliflorus, Biopolymer, Glycosyl linkage-composition, Lymphoproliferative activity, Macrophagestimulating activity

\section{Introduction}

The shoots and roots of various species of Acanthopanax (Araliaceae) have long been used as traditional medicines for many ailments, including diabetes, neuralgia, palsy, gastric ulcer, learning-behavior difficulties, and cancer in China, Korea, and Japan (Hahn et al., 1985; Yook et al., 1996;

*To whom correspondence should be addressed.

Tel: 82-53-850-6555; Fax: 82-53-850-6559

E-mail: chsong@daegu.ac.kr
Fujikawa et al., 1996). The biologically-active components of this plant have been previously investigated and various type of compounds have been isolated; e.g., phenylpropanoids, lignins, sterols, coumarins, and mono- and polysaccharides (Jones et al., 1972; Fang et al., 1985; Newall et al., 1996). In recent years, clinical studies have focused on polysaccharides, and these are believed to possess immuno-stimulatory, antiinflammatory (Zhou, 1985), and phagocytosis-stimulating activities (Fang et al., 1985). However, more detailed work is needed on the elucidation of the glycosyl linkage-compositions of active biopolymers, and on the immunologies of purified fractions of $A$. sessiliflorus biopolymer.

In the present investigation, we describe the macrophage enhancing and lymphocyte proliferating effects of biopolymers isolated from the dry bark of $A$. sessiliflorus. Active biopolymers were purified and natures of their glycosyl linkage-compositions were elucidated by GC-MS.

\section{Materials and Methods}

Preparation and purification of biopolymers. Dry bark of A. sessiliflorus was cut into small pieces pulverized and autoclaved for $2 \mathrm{~h}$. Preparation and isolation details are shown in Fig. 1.

The biopolymer solution was applied to a column $(6.6 \times 50 \mathrm{~cm})$ of DEAE Sepharose CL-6B, which had been equilibrated with $\mathrm{H}_{2} \mathrm{O}$, and eluted using a $0.1-1.0 \mathrm{M} \mathrm{NaCl}$ stepwise gradient until no sugar was detected in eluate.

Experimental animals and breeding conditions. Male 6-week mice (C57BL/6 and BALB/C strains) weighing approximately $25 \mathrm{~g}$ were purchased from Daehan Biolink, and housed in plastic cages. Mice were housed at constant temperature $\left(22 \pm 2^{\circ} \mathrm{C}\right)$ and humidity $(55 \pm 5 \%)$ under a $12 \mathrm{~h} \mathrm{light/dark} \mathrm{cycle.} \mathrm{Mice} \mathrm{were} \mathrm{fed} \mathrm{a} \mathrm{commercial}$ pellet diet (Sam Yang Co.) throughout the experimental period.

Preparation of mouse macrophages. Macrophages were harvested from mice three days after an intraperitoneal (i.p.) injection of $3 \mathrm{ml}$ of $10 \%$ thioglycolate medium. Cell density was adjusted to $1 \times 10^{6}$ cells/ $\mathrm{ml}$ with Dulbecco's modified eagle medium (DMEM) buffer 


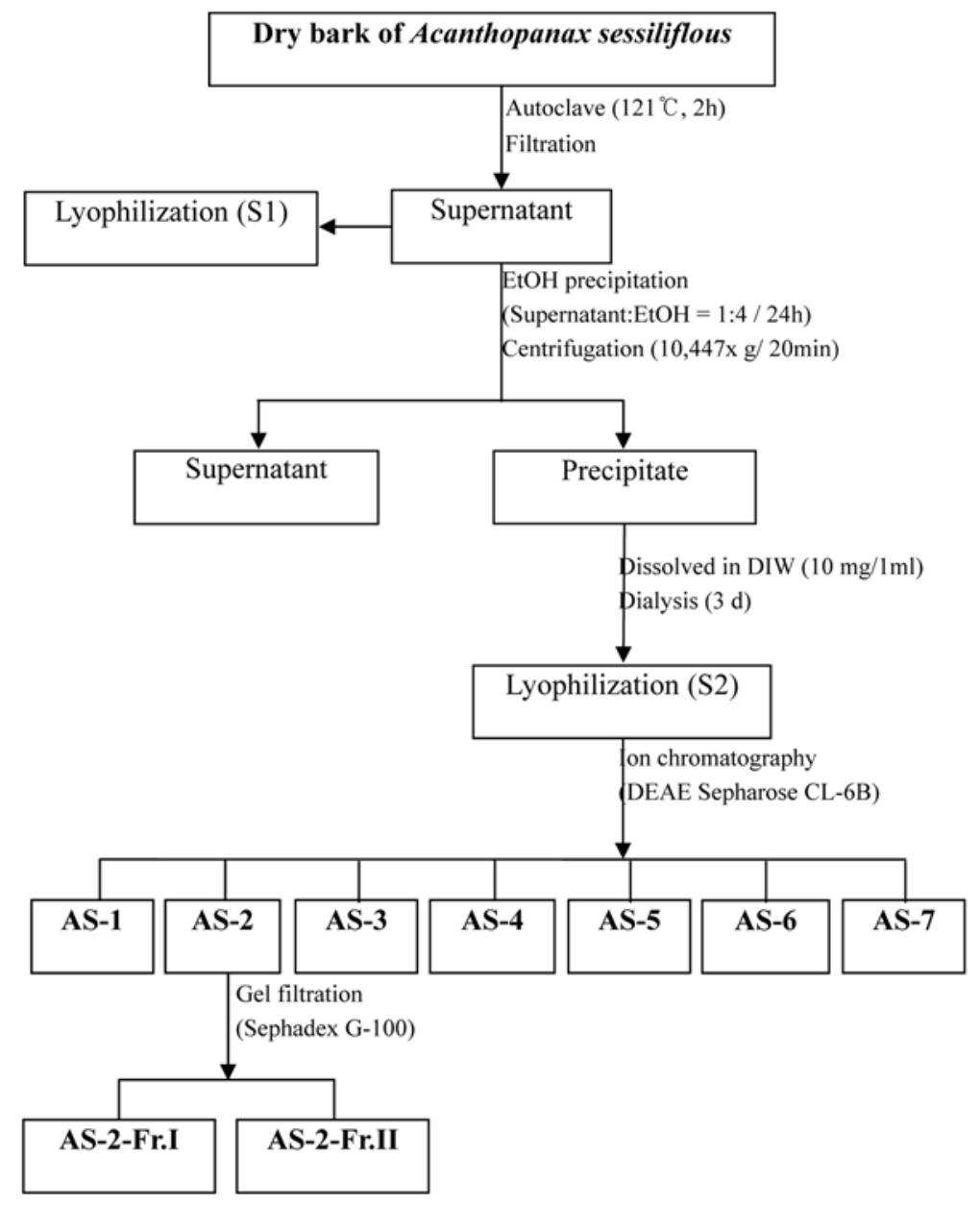

Fig. 1. A schematic diagram depicting the process used to recovery biopolymers from the dried bark of Acanthopanax sessiliflorus.

supplemented with $10 \%$ fetal bovine serum (FBS). Thereafter, each well of a 96-well microplate was inoculated with $200 \mathrm{ml}$ of the cell suspension $\left(2 \times 10^{5}\right.$ cells/well $)$. Adherent macrophages were isolated by incubating the cells for $2 \mathrm{~h}$ in $\mathrm{CO}_{2}$, and this was followed by vigorously shaking and washing the plate to remove non-adherent cells.

Cultures were incubated with or without test biopolymer additions, and in the absence or presence of interferon- $\gamma($ IFN- $\gamma ; 20 \mathrm{U} / \mathrm{ml})$ or lipopolysaccharide (LPS) at $37^{\circ} \mathrm{C}$ in a $5 \% \mathrm{CO}_{2}$ humidified incubator.

Determination of macrophage cellular lysosomal enzyme activity. Lysosomal enzyme activity was assayed using 96-well flatbottomed tissue culture plates (Suzuki et al., 1990). Macrophage monolayers in microplates $\left(2 \times 10^{5}\right.$ cells/well $)$ were solubilized by adding $25 \mu \mathrm{l}$ of $0.1 \%$ Triton X-100. p-nitrophenyl phosphate (PNPP) solution $(150 \mu \mathrm{l} ; 10 \mathrm{mM})$ was then added per well as a substrate for acid phosphatase, and this was followed by $50 \mu \mathrm{l}$ of citrate buffer/well. After incubating for $1 \mathrm{~h}$ at $37^{\circ} \mathrm{C}, 25 \mu \mathrm{l}$ of $0.2 \mathrm{M}$ borate buffer ( $\mathrm{pH} 9.8$ ) was added to each well, and optical densities were measured at $405 \mathrm{~nm}$.

Production of NO by biopolymer. Nitrite accumulation was used as an indicator of NO production, and levels were determined using the Griess reaction (Green et al., 1982). $100 \mu \mathrm{l}$ of culture supernatant (sodium nitrite) was mixed with an equal volume of Griess reagent
$[0.1 \%(\mathrm{w} / \mathrm{v})$ naphthyl ethylenediamine and $1 \%(\mathrm{w} / \mathrm{v})$ sulfanilamide in $5 \%(\mathrm{v} / \mathrm{v})$ phosphoric acid] in microplate wells, which were then allowed to stand for $5 \mathrm{~min}$ at room temperature. Optical densities were measured at $550 \mathrm{~nm}$ using an enzyme-linked immunosorbent assay (ELISA) reader.

Western blotting of iNOS. Aliquot of culture supernatant from each well were placed into new tubes, and stored at $-70^{\circ} \mathrm{C}$ prior to testing. Protein concentrations were determined using Bradford reagent (Biorad). Thirty $\mu$ of each supernatant were mixed with 5 volumes of loading buffer, boiled at $95^{\circ} \mathrm{C}$ for $5 \mathrm{~min}$, cooled, and then loaded onto $6 \%$ SDS-polyacrylamide gels. Separated proteins were transferred onto nitrocellulose (NC) membranes using a Mini V8-10 system. NC membranes were then blocked for $2 \mathrm{~h}$ at room temperature with $5 \%$ skimmed milk in Tris-buffered saline (TBS) containing $0.1 \%$ Tween-20 (TBST), they were then incubated overnight at $4^{\circ} \mathrm{C}$ in $0.25 \mu \mathrm{g} / \mathrm{ml}$ iNOS antibody diluted in $3 \%$ skimmed milk/TBS $(1 / 1000 ; \mathrm{v} / \mathrm{v})$. Membranes were washed five times in TBS and binding antibodies were detected using $0.06 \mu \mathrm{g} /$ $\mathrm{ml}$ sheep anti-mouse IgG horseradish peroxidase and the enhanced chemiluminescence (ECL) detection system (Amersham Biosciences).

Preparation of spleen cells. Mice were killed by cervical dislocation, and spleens were removed immediately and placed in 
cold Roswell park memorial institute-1640 (RPMI-1640) media. Spleen cells were extracted and separated using a $5 \mathrm{ml}$ syringe. Cell suspensions were washed three times in cold RPMI-1640 media, counted in $0.2 \%$ trypan blue, and adjusted to concentration. $\mathrm{T}$ and B lymphocytes were separated using the nylon wool enrichment method (Matthias et al., 2001).

Mixed lymphocyte culture (MLR). One-way lymphocyte cultures were prepared using a modification of the method described by Murgita \& Tamasi, (1975). Spleen cells from BABL/C mice at a density of $2 \times 10^{7}$ cells $/ \mathrm{ml}$ were incubated with mitomysin C (25 $\mu \mathrm{g} / \mathrm{ml})$ at $37^{\circ} \mathrm{C}$ for $30 \mathrm{~min}$, washed twice with cold Hank's balance salt solution (HBSS) containing 10\% FBS, reincubated for $10 \mathrm{~min}$ at $37^{\circ} \mathrm{C}$, and washed. Cells concentrations were adjusted to $6-8 \times$ $10^{7}$ cells $/ \mathrm{ml}$ before washing. Mitomysin C-treated cells served as 'stimulator' cells. A second set of spleen cells were prepared from C57BL $/ 6$ mice and adjusted to a concentration of $4 \times 10^{7}$ cells $/ \mathrm{ml}$ to serve as 'responder' cells. One-way mixed lymphocyte cultures were prepared with $2 \times 10^{6}$ stimulator cells plus $2 \times 10^{6}$ responder cells in $200 \mu$ of RPMI-1640 media in 96-well flat-bottom culture plates. Three replicates of each cell type or combination were made. Plates were incubated in $5 \% \mathrm{CO}_{2}$ at $37^{\circ} \mathrm{C}$ for $72 \mathrm{~h}$. Methylthiazoletetrazolium (MTT) was added $4 \mathrm{~h}$ prior to the termination of culture. After this incubation, plates were centrifuged at 3,000 rpm for $20 \mathrm{~min}$. in order to precipitate insoluble formazan. After discarding the supernatant, $0.1 \mathrm{ml}$ of dimethyl sulfoxide (DMSO) were added to each well to solubilize the formazan and optical densities were measured at $540 \mathrm{~nm}$ using an ELISA reader.

Methylation of biopolymer. Biopolymer fractions were methylated using the Hakomori method (1962). Briefly, biopolymer (2 mg) was dissolved in DMSO $(0.1 \mathrm{ml})$ by ultrasonication in a nitrogen atmosphere, treated with methylsulfinyl carbanion $(0.1 \mathrm{ml})$ for $4 \mathrm{~h}$ at room temperature, and then with methyl iodide $(0.1 \mathrm{ml})$ for $12 \mathrm{~h}$ at room temperature. Methylated biopolymer fractions were purified by using a Sep-pak $\mathrm{C}_{18}$ cartridge (Waters Assoc.), and permethylated biopolymers were hydrolyzed with $2 \mathrm{M}$ trifluoroacetic acid $(1.5 \mathrm{ml})$ for $1 \mathrm{~h}$ at $121^{\circ} \mathrm{C}$, reduced with sodium borohydride, and acetylated. The resulting methylated alditol acetates were analyzed by gas liquid chromatography (GLC) and gas liquid chromatography-mass spectrometry (GLC-MS). GLC was performed on a Varian model STAR 3600CX gas chromatograph equipped with a flame-ionization detector on a $\mathrm{SP}^{\mathrm{TM}}-2380$ capillary column $(30 \mathrm{~m} \times 0.25 \mathrm{~mm}$ i.d., $0.2-\mu \mathrm{m}$ film: SUPELCO). Nitrogen was used as a carrier gas (15 psi). The detector and column oven were operated at $260^{\circ} \mathrm{C}$. GLCMS (at $70 \mathrm{eV}$ ) was performed using a Shimadzu QP5050 instrument equipped with the same capillary column. GLC peaks were identified using relative retention times and GC-MS data. Mol\% values for sugars were determined from peak areas.

\section{Results and Discussion}

\section{Macrophage activation effect}

Effects of biopolymers on lysosomal enzyme activity. Lysosomal enzyme and phagocytic activities are crucial aspects of macrophage functional assessments (Wang et al.,

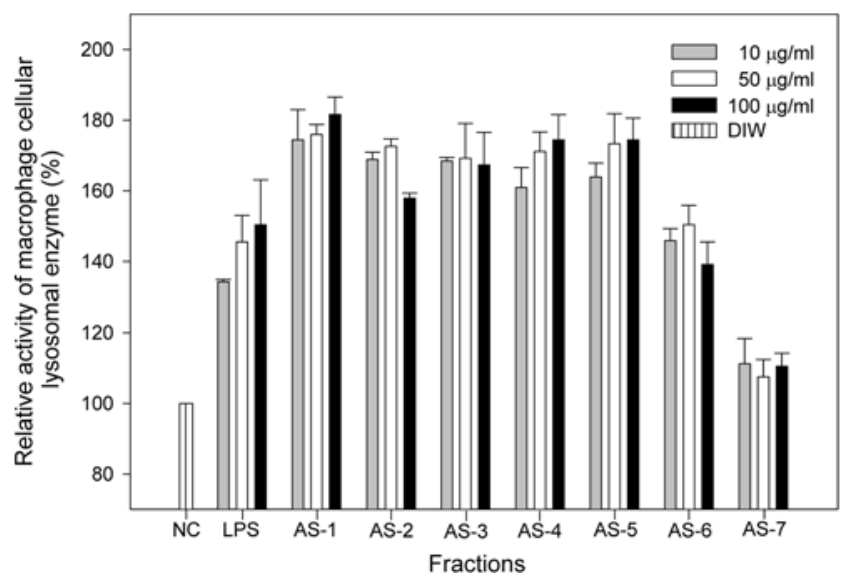

Fig. 2. Macrophage cellular lysosomal enzyme activities of biopolymers extracted from the dried bark of Acanthopanax sessiliflorus. NC: Saline was used in the negative control. LPS: Positive control (lipopolysaccharide from Escherichia coli 0127: B8). The macrophage concentration was $1 \times 10^{6}$ cells $/ \mathrm{ml}$.

1993). The production of lysosomal acid phosphatases (lysosomal enzymes) by mononuclear phagocytes occurs in response to numerous exogenous stimuli (Page et al., 1978). Here, we examined the effects of biopolymer fractions (AS-1 to AS-7) isolated from A. sessiliflorus on the lysosomal enzyme activities of peritoneal macrophages. The cellular lysosomal activities of these fractions at various concentrations are shown in Fig. 2. It was found that two fractions (AS-1 and AS-5) exhibited higher activity than the other fractions. At concentrations of 10,50 , and $100 \mu \mathrm{g} / \mathrm{ml}$ the AS- 1 and AS-5 fractions increased the relative enzyme activity by 165,173 , 174 , and $175,177,182 \%$, respectively, versus negative (physiological saline) controls.

Figure 3 shows lysosomal enzyme activities after stimulation with AS-1 or AS-5. Enzymatic activity in the presence of AS5 was higher than in the presence of AS-1 at $300 \mu \mathrm{g} / \mathrm{ml}$, presumably because AS-5 promotes the lysing of foreign substances engulfed by macrophages more efficiently. Thus, we suggest that the biopolymer fraction (AS-5) of $A$. sessiliflorus should be viewed as a potent means of enhancing innate immune response. Moreover, this effect of $A$. sessiliflorus biopolymer was similar that of the biopolymer extracted from the fruiting bodies of Agaricus bisporus on the production of cellular lysosomal enzyme in mouse macrophages (Kim et al., 1998). It was also reported that the polysaccharides from the fruiting bodies of Armillariella tabescens have antitumor activity on sarcoma 180, and that this is related to lysosomal enzyme activation in macrophages (Tsukagoshi \& Ohashi, 1974).

Effects of biopolymers on the production of nitric oxide (NO). The stimulatory effects of partially purified biopolymers from A. sessiliflorus on the production of the nitric oxide were also examined. The stimulation of murine macrophages results in the expression of an inducible nitric oxide synthase (iNOS), 


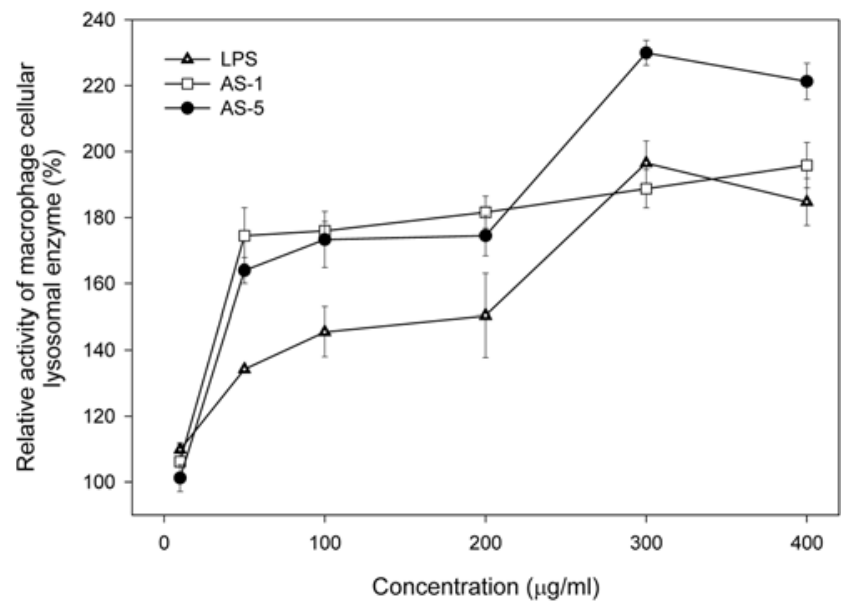

Fig. 3. Effects of AS-1 and AS-5 on the cellular lysosomal enzyme activity of mouse peritoneal macrophages. NC: Saline was used in the negative control. LPS: Positive control (lipopolysaccharide from Escherichia coli 0127: B8). The macrophage concentration was $1 \times 10^{6}$ cells $/ \mathrm{ml}$. Symbols: (A) LPS, ( $\square)$ AS-1, (○) AS-5.

which catalyzes the production of a large amount of NO from L-arginine and molecular oxygen (Hibbs et al., 1987). The seven fractions of biopolymer isolated (AS-1 to AS-7) in the present study were found to increase NO production by macrophages, and the AS-5 fraction proved to be most potent in this LPS and IFN- $\gamma$ are internal and external activators of murine macrophage, respectively (Watanabe, 2005). As shown in Fig. 4(A), when macrophages were incubated with AS-5 after being pretreated with IFN- $\gamma$ or IFN- $\gamma$ plus LPS, NO releasing activities were $27 \mu \mathrm{M}$ and $58 \mu \mathrm{M}$, respectively. Also, AS-5 was able to activate NO release under IFN- $\gamma$ depleted conditions, indicating that AS-5 can induce NO production by macrophage by itself.

Since, AS-5 augments the abilities of IFN- $\gamma$ or LPS to increase macrophage activity, AS-5 could provide a second signal for synergistic induction of NO synthesis in macrophages, and may act synergistically with other mitogens in host defense system's against microbial infection.

To confirm iNOS protein expression, western blotting was carried out after incubating AS-5 with IFN- $\gamma$ and/or LPS in peritoneal macrophages. The effect of AS-5 in combination with IFN- $\gamma$ and LPS on the expression of iNOS protein in $\mathrm{C} 57 \mathrm{BL} / 6$ mouse peritoneal macrophages is presented in Fig. 4(B), which shows synergistic increase in iNOS protein expression in the presence of AS-5 with IFN- $\gamma$ and/or LPS.

Nitric oxide is a potent macrophage-derived effector molecule against a variety of bacteria, parasites, and tumors (Stuehr et al., 1989; Nathan \& Hibbs 1991). It is known that macrophages produce some reactive oxygen species (ROS) during the phagocytic process, and $\mathrm{O}_{2}^{-}, \mathrm{H}_{2} \mathrm{O}_{2}$, and $\mathrm{NO}$ are considered to be important for the killing of foreign organisms (Kasravi et al., 1996; Roszell \& Rice, 1998).

Phagocytosis is the first step in the response of macrophages

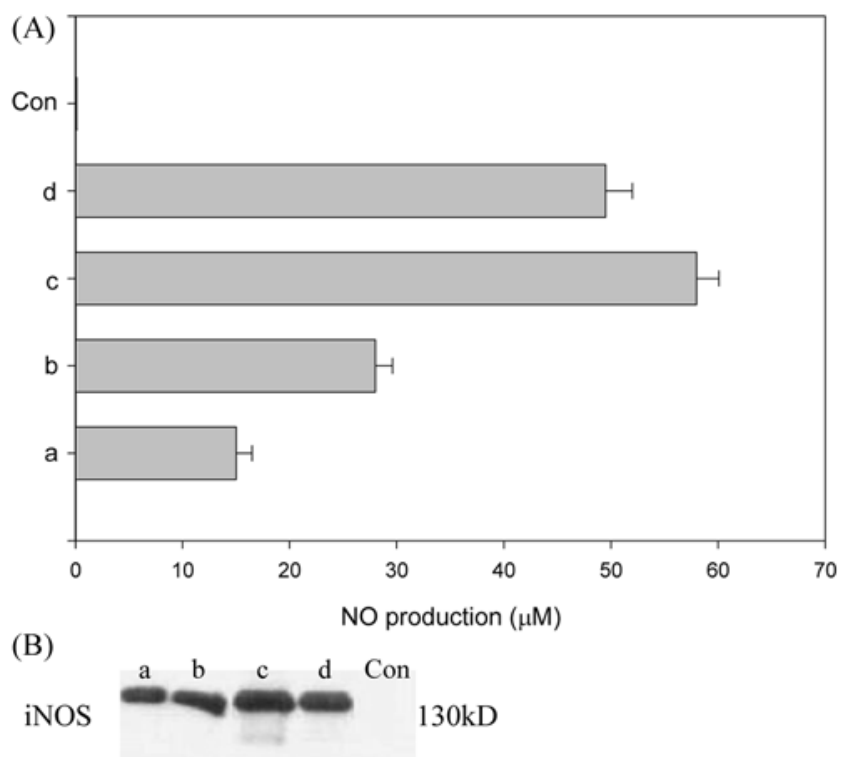

Fig. 4. Effects of AS-5 on NO production by and iNOS expression in mouse peritoneal macrophages under different conditions. Cells were incubated with AS-5 (a), IFN- $\gamma+$ AS-5 (b), IFN- $\gamma+$ LPS + AS-5 (c), IFN- $\gamma+$ LPS (d), or saline (Con: control). (A) Production of nitric oxide. LPS: Positive control (lipopolysaccharide from Escherichia coli 0127: B8). IFN- $\gamma$ : Potent activator of macrophage. The macrophage concentration was $2 \times 10^{6}$ cells $/ \mathrm{ml}$. (B) Expression of iNOS. Protein extracts were prepared, and $15 \mathrm{mg}$ of total protein was loaded into each lane and analyzed for iNOS expression by Western blotting as described in Methods.

to invading macroorganisms.

As stated previously, we found that AS-5 has strong lysosomal enzyme activity, and this and our other results suggest that AS-5 of A. sessiliflorus has macrophage activating capacity. Therefore, we conclude that treatment with AS-5 might augment innate immune response.

\section{Splenocyte proliferation activity}

Effects of biopolymers on splenocyte proliferation activity. The immune responses of splenocytes responding to alloantigens were determined by MLR. In the present study, highest lymphoproliferation activity was exhibited by AS-6, followed by AS3 and AS-5 (Fig. 5).

When the activities of the biopolymers fractions were compared with those of another lymphocyte mitogen (LPS), we found that the lymphoproliferative abilities of the $A$. sessiliflorus biopolymers at concentrations of 10, 50, and 100 $\mu \mathrm{g} / \mathrm{ml}$ were higher than that of LPS at same concentrations. As shown in Fig. 5, highest lymphoproliferative activity was achieved by AS-6 at $100 \mu \mathrm{g} / \mathrm{ml}$, which represented a 2.4-fold enhancement versus the saline control. Thus, proliferative effects of biopolymers (AS-3, 5 and 6) were tested at higher concentration levels.

Maximum lymphocyte proliferative activity was observed for AS-3 at $200 \mu \mathrm{g} / \mathrm{ml}$, which represented a 2.5-fold enhancement, 


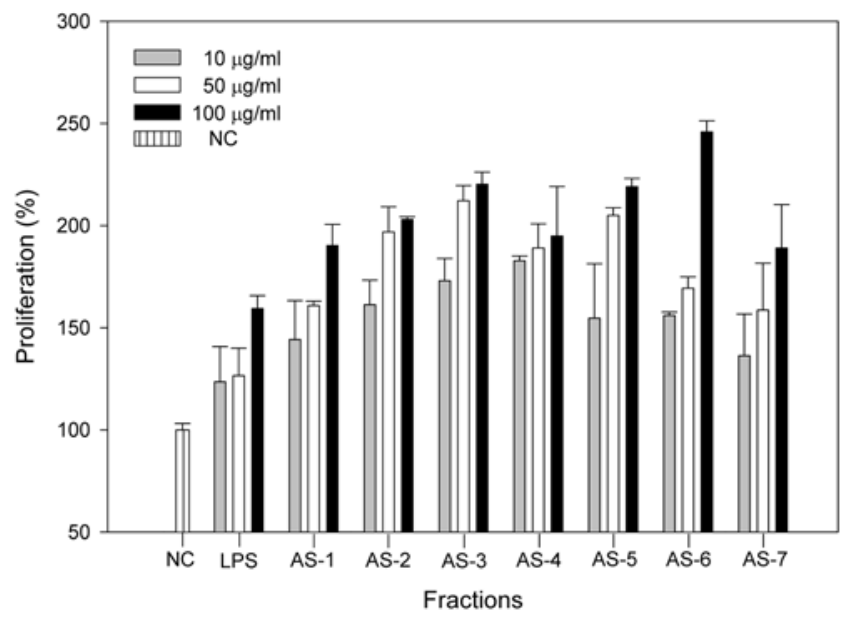

Fig. 5. Effects of the biopolymers extracted from the dried bark of Acanthopanax sessiliflorus on splenocyte proliferation, as determined using mixed lymphocyte reactions. NC: Saline was used in the negative control. LPS: Positive control (lipopolysaccharide from Escherichia coli 0127: B8). Mouse splenocyte proliferations were measured after incubating for 96 hours using the MTT method. The splenocyte concentration was $2 \times 10^{6}$ cells $/ \mathrm{ml}$.

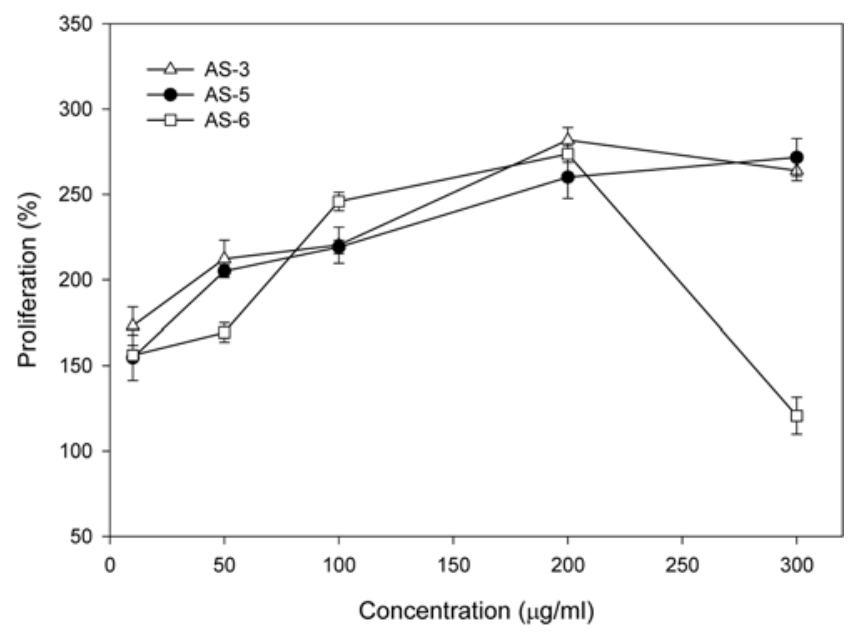

Fig. 6. Effects of the biopolymers extracted from the dried bark of Acanthopanax sessiliflorus on splenocyte proliferation, as determined using the mixed lymphocyte reaction. Mouse splenocyte proliferations were measured after incubating for 96 hours by using the MTT method. The splenocyte concentration was $2 \times 10^{6}$ cells $/ \mathrm{ml}$. Symbols: $(\triangle)$ AS-3, $(\bigcirc)$ AS-5, $(\square)$ AS-6.

and this decreased at concentrations $>200 \mu \mathrm{g} / \mathrm{ml}$ (Fig. 6), and AS-6 showed a similar but more rapid decrease in proliferative activity at concentration $>200 \mu \mathrm{g} / \mathrm{ml}$. Whereas, AS-5 was increased activity in a concentration-dependent manner at concentrations $>300 \mu \mathrm{g} / \mathrm{ml}$.

T and B lymphocytes proliferation activity. The lymphoproliferative potential of the biopolymer fractions was also studied in $\mathrm{T}$ and B lymphocytes. As shown in Fig. 7, the

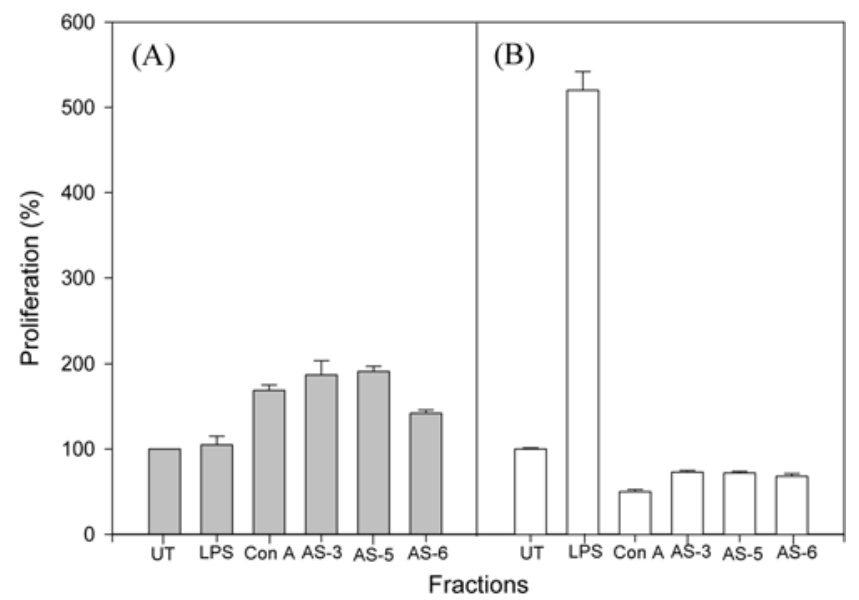

Fig. 7. Effects of biopolymers extracted from the dried bark of Acanthopanax sessiliflorus on the proliferations of $\mathrm{T}$ and $\mathrm{B}$ lymphocytes. (A) T lymphocyte proliferation (B) B lymphocyte proliferation. UT: Untreated group. Con-A: Concanavalin A was used in the T lymphocyte positive control. LPS: Lipopolysaccharide (Escherichia coli 0127: B8) was used in the B lymphocyte positive control. Lymphocytes proliferation was measured after incubating for 96 hours by using the MTT method. The lymphocyte concentration was $2 \times 10^{6}$ cells $/ \mathrm{ml}$.

activities of LPS or concanavalin A (Con-A) treated groups were quite different from those of T (Fig. 7(A)) and B (Fig. 7(B)) lymphocytes.

The number of $\mathrm{T}$ lymphocytes in the Con-A treated group was 1.7-fold that of the control group. However, the proliferation of $\mathrm{T}$ lymphocyte was not changed by LPS. These results indicate that $\mathrm{T}$ and $\mathrm{B}$ lymphocytes were successfully separated from splenocyte. In particular, T lymphocyte proliferations induced by AS-5, AS-3 or AS- 6 were increased by 191, 187 and $142 \%$, respectively. However, B lymphocyte proliferations by these respective biopolymers were increased by 73, 72 and $68 \%$, respectively. Therefore, biopolymers of $A$. sessiliflorus have a mitogenic effect on $\mathrm{T}$ lymphocyte, but not on $\mathrm{B}$ lymphocyte.

Although Acanthopanax species-derived polysaccharides have been previously shown to increase splenocyte proliferation and in vivo T-dependent antibody response (Shen et al., 1991; Wang et al., 1991, 1993), it remained unclear as to whether they act directly as B and/or T lymphocytes activators, since total spleen cell populations were used in this study. Polysaccharides represent a structurally diverse class of macromolecules, and this structural variability can profoundly affect their cell-type specificities, especially with respect to $\mathrm{T}$ and B lymphocytes. For example, $\beta(1 \rightarrow 3)$-glucans isolated from $L$. edodes and $S$. commune were found to stimulate $\mathrm{T}$ lymphocyte but not B lymphocyte (Maeda et al., 1988; Suzuki et al., 1994; Borchers et al., 1999), whereas polysaccharides from $P$. linteus activated both $\mathrm{B}$ and $\mathrm{T}$ lymphocytes (Kim et al., 1996), and other polysaccharides from $P$. grandiflorum and $A$. gigas Naki were found to 
Table 1. Identification of partially methylated alditol acetates in the major active biopolymers of Acanthopanax sessiliflorus

\begin{tabular}{|c|c|c|c|c|}
\hline \multirow{2}{*}{ Methylated sugar } & \multirow{2}{*}{ Major mass spectral fragments $(\mathrm{m} / \mathrm{e})^{b}$} & \multicolumn{2}{|c|}{$\operatorname{Mol}^{a}{ }^{a}$} & \multirow{2}{*}{ linkages } \\
\hline & & AS-3 & AS-5 & \\
\hline 2,4,6-tri-O-Me-D-Glc & $43,45,87,101,117,129,161,233$ & - & 10.9 & $\rightarrow{ }^{3} \mathrm{Glc}^{1} \rightarrow$ \\
\hline 2,3,6-tri-O-Me-D-Glc & $43,87,99,101,117,129,161,189,233$ & - & 5.0 & $\rightarrow^{4} \mathrm{Glc}^{1} \rightarrow$ \\
\hline 2,3,4-tri-O-Me-D-Glc & $43,45,87,99,101,113,117,233$ & 10.7 & 3.1 & $\rightarrow{ }^{6} \mathrm{Glc}^{1} \rightarrow$ \\
\hline 2,3,5,6-tetra- $O$-Me-Gal & $43,71,87,117,129,145,173,205$ & 12.6 & - & $\rightarrow{ }^{4} \mathrm{Gal}^{1} \rightarrow$ \\
\hline 2,3,4,6-tetra- $O$-Me-Gal & $43,89,101,129,161,205$ & 2.2 & - & $\mathrm{Gal}^{1} \rightarrow$ \\
\hline 2,3,6-tri-O-Me-D-Gal & $43,87,99,101,117,129,161,189,233$ & 1.6 & 20.1 & $\rightarrow{ }^{4} \mathrm{Gal}^{1} \rightarrow$ \\
\hline 2,3,4-tri-O-Me-D-Gal & $145,161,189,233$ & 24.5 & 5.2 & $\rightarrow{ }^{6} \mathrm{Gal}^{1} \rightarrow$ \\
\hline 3,4,5-tri-O-Me-D-Gal & $87,101,117,161,189$ & - & 3.7 & $\rightarrow{ }^{2,6} \mathrm{Gal}^{1} \rightarrow$ \\
\hline 2,4-di-O-Me-D-Gal & $43,87,117,129,189$ & - & 2.5 & $\rightarrow{ }^{3,6} \mathrm{Gal} \rightarrow$ \\
\hline 2,4-di-O-Me-D-Man & $87,101,129,159,189$ & - & 10.3 & $\rightarrow^{3,6} \operatorname{Man}^{1} \rightarrow$ \\
\hline 4-O-Me-Man & $43,87,117,129,189$ & - & 1.7 & $\rightarrow^{2,3,6} \mathrm{Man} \rightarrow$ \\
\hline 2,3,5-tri- $O$-Me-Ara & $43,45,101,117$ & 6.0 & 8.7 & $\mathrm{Ara}^{1} \rightarrow$ \\
\hline 2,3-di-O-Me-Xyl & $87,101,117,129,189$ & 5.1 & - & $\rightarrow{ }^{4} \mathrm{Xyl}^{1} \rightarrow$ \\
\hline 2-O-Me-Ara & $43,117,127,201,261$ & 10.9 & - & $\rightarrow^{3} \mathrm{Ara}^{1} \rightarrow$ \\
\hline
\end{tabular}

${ }^{a}$ Calculated from peak areas and response factors obtained using a hydrogen flame ionization detector (Sweet, Shapiro, \& Albersheim, 1975).

${ }^{b}$ Fragments were obtained from the GC-MS spectra of methylated alditol acetates using a Shimazu QP5050 MS unit.

The excluded unidentified peaks may represent multi-branched sugars or they may have been the consequence of slight under-methylation.

activate only B lymphocyte (Han et al., 1998). The results of the present study show that A. sessiliflorus biopolymers selectively and efficiently activate macrophages and $\mathrm{T}$ lymphocyte, but not B lymphocyte.

Moreover, the observed proliferation-enhancing pattern shown by AS-5 is similar to that described for lentinan (Borchers et al., 1999), and shizophyllan (Ooi et al., 2000; Suzuki et al., 1994). Schizophyllan was found to restore and enhance cellular immunity in tumor-bearing hosts by functioning as a $\mathrm{T}$ cell adjuvant and macrophage activator (Haba et al., 1976).

Structural analysis of major active biopolymers. The prepared methylated alditol acetates of AS-3 and AS-5 were analyzed by GC-MS and glycosidic linkages were determined. Individual methylated alditol acetates were identified by relative retention times and by comparing mass spectrum fragment ion $(\mathrm{m} / \mathrm{z})$ abundances with the MS database library. Predominant peaks of AS-3 and AS-5 were also characterized (Table 1).

AS-3 and AS-5 fractions contained mainly 2,3,4-tri- $O$ methyl-D-glucitol, 2,3,4-tri- $O$-methyl-D-galacitol, 3,4,6-tri- $O$ methyl-galacitol, and 2-O-methyl-arabinitol, and 2,4,6-tri- $O$ methyl-D-glucitol, and 2,3,6-tri- $O$-methyl-D-galacitol, respectively, indicating that AS-3 shows contains more ' $G a l$ ' branching than the other active fractions. The fundamental structures of biopolymers of $A$. sessiliflorus were found to consist of galactose, arabinose, glucose, mannose, and rhamnose connected in various ways. Several types of immuno-modulatory polysaccharide have been reported to contain $\beta-(1 \rightarrow 3)$ glucan, and glycoproteins containing $\alpha, \beta(1 \rightarrow 3), \alpha, \beta(1 \rightarrow 4)$, and $\alpha, \beta(1 \rightarrow 6)$ glucosidic linkages (Yamada et al., 1985; Ukai et al., 1982; Miura et al., 1996), galactose $\beta-(1 \rightarrow 3)$ (Kawaguci et al., 1986), arabino-3,6-galactan (Yu et al., 2000), and rhamnogalacturonan (McNeil et al., 1984). Based on these results, it might be supposed that the immunomodulatory activities of AS-3 and AS-5 are due to the presences of glucose $(1 \rightarrow 3)$ and $(1 \rightarrow 4)$ linkages, and of arabinogalactan and rhamnogalactan.

Acknowledgments This work was supported by a Daegu University research grant, 2004.

\section{References}

Borchers, A. T., Stern, J. S., Hackman, R. M., Keen, C. L. and Gershwin, M. E. (1999) Mushrooms, tumors, and immunity. Proc. Soc. Exp. Biol. Med. 221, 281-293.

Fang, J. N., Proksch, A. and Wagner, H. (1985) Immunologically activity polysaccharides of acanthopanax senticosus. Phytochemistry 24, 2619-2622.

Fujikawa, T., Yamaguchi, A., Morita, I., Takeda, H. and Nihshibe, S. (1996) Protective effects of Acantopanax senticosus Harms from Hokkai do and its components on gastric ulcer in restrained cold water stressed rats. Biol. Pharm. Bull. 19, 12271230.

Green, L. C., Wanger, D. A., Glogowski, J., Skipper, P. L., Wishnok, J. S. and Tannenbaum, S. R. (1982) Analysis of nitrite, and $\left[{ }^{15} \mathrm{~N}\right]$ nitrate in biological fluids. Anal. Biochem. 126, 131-136.

Haba, S., Hamaoka, T., Takatsu, K. and Kitagawa, M. (1976) 
Selective suppression of T-cell activity in tumor-beraing mice and its improvement by lentinan, a potent anti-tumor polysaccharide. Int. J. Cancer 18, 93-104.

Hahn, D. R., Kim, C. J. and Kim, J. H. (1985) A study on chemical constituents of Acanthopanax koreanum Nakai and its pharmaco-biological activities. Yakhak Hoeji 29, 357-361.

Hakomori, S. I. (1964). A rapid permethylation of glycolipid, and polysaccharide catalyzed by methyl sulphinyl carbanion in dimethyl sulfoxide. J. Biochem. 55, 205-208.

Han, S. B., Kim, Y. H., Lee, C. W., Park, S. M., Lee, H. Y., Ahn, K. S. and Kim, H. M. (1998) Characteristic immunostimulation by angelan isolated from Angelica gigas Nakai. Immunopharmacology 40, 39-48.

Hibbs, J. B., Taintor, R. R. and Vavrin, Z. (1987) Macrophage cytotoxicity: role for L-arginine deiminase and imino nitrogen oxidation to nitrite. Science 235, 473-476.

Jones, T. M. and Albersheim, P. O. (1972) A gas chromatographic method for the determination of aldose and uronic acid constituents of plant cell wall polysaccharides. Plant Physiol. 49, 926-936.

Kasravi, F. B., Gebreselassie, D., Adawi, D., Wang, L. Molin, G., Bengmark, S. and Jeppsson, B. (1996) The effect of endotoxin and Lactobacillus pretreatment on peritoneal macrophage behavior in acute liver injury in rat. J. Surgical Res. 62, 63-68.

Kawaguchi, N., Ohmori, T., Takeshita, Y., Kawanishi, G., Katayama, S. and Yamada, H. (1986) Occurrence of Gal beta $(1 \rightarrow 3)$ GalNAc-Ser/Thr in the linkage region of polygalactosamine containing fungal glycoprotein from Cordyceps ophiolssoides. Biochem. Biophys. Res. Comm. 140, 350-356.

Kim, B. H., Kweon, M. H., Lim, W. J., Song, H. C. and Yang. H. C. (1998) Structural characterization of the anti-complementary and macrophage activating polysaccharides isolated from Agaricus bisporus. Korean J. Food Sci. Technol. 30, 709-716.

Kim, H. M., Han, S. B., Oh, G. T., Kim, Y. H., Hong, D. H, Hong, M. D. and Yoo, I. D. (1996) Stimulation of humoral and cell mediated immunity by polysaccharide from mushroom Phellinus linteus. Int. Immunopharmacol. 18, 295-303.

Maeda, Y. Y., Watanabe, S. T., Chihara, C. and Rokutanda, M. (1988) Denaturation and renaturation of a beta-1,6; 1,3-glucan, lentinan, associated with expression of T-cell-mediated responses. Cancer Res. 48, 671-675.

Matthias, G., Carsten, W., Lourdes, P. and Stephan, G. (2001) Two-step negative enrichment of CD4+ and CD8+ $\mathrm{T}$ cells from murine spleen via nylon wool adherence and an optimized antibody cocktail. J. Immunol. Methods 258, 55-63.

McNeil, M., Darvill, A. G., Fry, S. C. and Albershim, P. (1984) Structure and function of the primary cell walls of plants. Annu. Rev. Biochem. 53, 625-663.

Miura, N. N., Ohno, N., Aketagawa, J., Tamura, H., Tanaka, S. and Yadomae, T. (1996) Blood clearance of $(1 \rightarrow 3)-\beta$-Dglucan in MRL lpr/lpr mice. FEMS Immunol. Med. Microbiol. 13, 51-57.

Murgita, R. A. and Tamasi, T. B. (1975) Suppression of the immune response by alphafetoprotein: II. The effect of mouse a-fetoprotein on mixed lymphocyte reactivity and mitogeninduced lymphocyte transformation. J. Exp. Med. 141, 440-452.

Nathan, C. F. and Hibbs, J. B. (1991) Role of nitric oxide synthesis in macrophage antimicrobial activity. Curr. Opin. Immunol. 3, 65-70.

Newall, C. A., Anderson, L. A. and Pillipson, J. D. (1996) Herbal
Medicines. A Guide for Health-Care Professionals, The Pharmaceutical Press, London.

Ooi, V. E. and Liu, F. (2000) Immunomodulation and anti-cancer activity of polysaccharide-protein complexs. Curr. Med. Chem. 7, 715-729.

Page, R. C., Davies, P. and Allison, A. C. (1978) The macrophage as a secretory cell. Int. Rev. Cytol. 52, 119-123.

Roszell, L. E. and Rice, C. D. (1998) Innate cellular immune function of anterior kidney leucocytes in the gulf killifish, Fundulus grandis. Fish Shellfish Immunol. 8, 129-142.

Shen, M. L., Zhai, S. K., Chen, H. L., Luo, Y. D. and Tu, G. R. (1991) Immunopharmacological effects of polysaccharides from Acanthopanax senticosus on experimental animals. Int. J. Immunopharmacol. 13, 549-554.

Stuehr, D. J. and Nathan, C. F. (1989) Nitric oxide. A macrophage product responsible for cytostasis and respiratory inhibition in tumor target cells. J. Exp Med. 169, 1543-1555.

Suzuki, H., Hyama, K., Yoshida, O., Yamazaki, S., Yamamoto, N., and Toda, S. (1990) Structural characte4rization of the immunoreactive and antiviral water-solubilized lignin in an extract of the culture medium of Lentinus edodes mycelia (LEM). Agric. Biol. Chem. 54, 479-487.

Suzuki, M., Iwashiro, M., Takatsuki, F., Kuribayashi, K. and Hamuro, J. (1994). Reconstitution of anti-tumor effects of lentinan in nude mice: role of delayed-type hypersensitivity reaction triggered by $\mathrm{CD} 4$-positive $\mathrm{T}$ cell clone in the infiltration of effector cells into tumor. Jpn. J. Cancer Res. 85, 409-417.

Tsukagoshi, S. and Ohashi. F. (1974) Protein-bound polysaccharide preparation, PS-K, effective against mouse sarcoma 180 and rat ascites hepatoma AH-13 by oral use. Gann 65, 557-558.

Ukai, S., Yokoyama, S., Hara, C. and Kiho, T. (1982) Structure of an alkali-soluble polysaccharide from the fruit body of Ganoderma japonicum Lloyd. Carbohydr. Res. 105, 237-245.

Wang, J. Z., Mao, X. J., Ito, H. and Shimura, K. (1991) Immunomodulatory activity of polysaccharide from Acanthopanax obovatus roots. Plant Med. 57, 335-336.

Wang, G., Zhang, J., Mizuno, T., Zhuang, C., Ito, H., Mayuzumi, H., Okamoto, H. and Li, J. (1993) Antitumor active polysaccharides foreo the Chinese mushroom song-shan lingzhi, the fruiting body of Ganoderma tsugae. Biosci. Biotechnol. Biochem. 57, 894-900.

Watanabe, K. (2005) Differentiation by LPS and IFN- $\gamma$ of expression of adenosine receptors in macrophage cell lines RAW264 and J774. Pediatric Den. J. 15, 43-51.

Yamada, H., Kiyohara, H., Cyong, J. C. and Otsuka, Y. (1985) Studies on the polysaccharides from Angelica acutiloba. IV. Characterization of an anti-complementary arabinogalactan from the roots of Angelica acutiloba Kitakawa. Mol. Immunol. 22, 295-304.

Yook, C. S., Rho, Y. S., Sed, S. H., Leem, J. Y. and Han, S. H. (1996) Chemical components of Acanthopanax divaricatus and anticancer effect in leaves. Yakhak Hoeji 40, 251-261.

Yu, G. D., Yin, Q. Z. and Hu, Y. M. (1996) Effects of Coriolus versicolor polysaccharides peptides on electric activity of mediobasal hypothalamus and on immune function in rats. Zhongguo Yao Li Bue Bao 17, 271-274.

Zhou, C. C. (1985) Anti-inflammatory action of ethanol extracts from Acanthopanax sessiliflorus. Chung Yao Tung Pao 10, 3741. 